\title{
Correction to: Germline variants in hereditary breast cancer genes are associated with early age at diagnosis and family history in Guatemalan breast cancer
}

\author{
Megan Ren ${ }^{1} \cdot$ Anali Orozco ${ }^{2} \cdot$ Kang Shao $^{3,5} \cdot$ Anaseidy Albanez $^{2} \cdot$ Jeremy Ortiz $^{2} \cdot$ Boyang Cao $^{3} \cdot$ Lusheng Wang $^{4,5}$. \\ Lilian Barreda $^{6}$. Christian S. Alvarez ${ }^{1}$. Lisa Garland ${ }^{7}$. Dongjing Wu ${ }^{7}$. Charles C. Chung ${ }^{7,9} \cdot$ Jiahui Wang ${ }^{7}$.

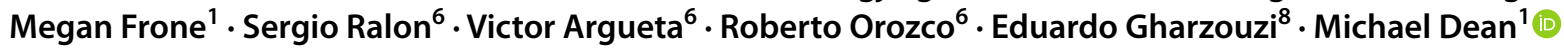

Published online: 9 November 2021

(c) Springer Science+Business Media, LLC, part of Springer Nature 2021
Publisher's Note Springer Nature remains neutral with regard to jurisdictional claims in published maps and institutional affiliations.

In the original publication, one of the authors Dr Kang Shao's affiliation was missed and the same has been provided in this correction.

The original article can be found online at https://doi.org/10.1007/ s10549-021-06305-5.

\footnotetext{
Roberto Orozco

roberto.orozco@yahoo.com

$\triangle$ Eduardo Gharzouzi

drnaufal@gmail.com

$\triangle$ Michael Dean

deanm@mail.nih.gov

1 Division of Cancer Epidemiology and Genetics, National Cancer Institute, NIH, Gaithersburg, MD, USA

2 Instituto Cancerologia, Guatemala City, Guatemala

3 BGI-Shenzhen, Beishan Industrial Zone, Shenzhen 518083, People's Republic of China

4 City University of Hong Kong Shenzhen Research Institute, Shenzhen, People's Republic of China
} 